\title{
Strategies of the beetle Oochrotus unicolor (Tenebrionidae) thriving in the waste dumps of seed-harvesting Messor ants (Formicidae)
}

\author{
THOM A S PARM E N T ER, ${ }^{1,2,3}$ M I Q U E L G A J U-R I C A R T, ${ }^{4}$ \\ T O M W E N ELEER S ${ }^{2}$ and RAFAEL M O LERO-B A LTA N Á S ${ }^{4}{ }^{1}$ Terrestrial \\ Ecology Unit (TEREC), Department of Biology, Ghent University, Ghent, Belgium, ${ }^{2}$ Laboratory of Socioecology and \\ Socioevolution, KU Leuven, Leuven, Belgium, ${ }^{3}$ Research Unit of Environmental and Evolutionary Biology, Namur Institute of \\ Complex Systems, and Institute of Life, Earth, and the Environment, University of Namur, Namur, Belgium and ${ }^{4}$ Deptartamento de \\ Zoología, University of Córdoba, Córdoba, Spain
}

\begin{abstract}
A diverse group of arthropods have adapted to the niches found inside the nests of social insects. Studies mostly focused on very specialised parasites residing in the brood chambers. However, the biology and strategies of symbionts occupying other niches, such as waste dumps, are underexplored.

2. Using a series of complementary experiments, this study demonstrated that the Mediterranean beetle Oochrotus unicolor has adapted to the waste dump niche found in the nests of Messor harvester ants.

3. Laboratory experiments confirmed field observations that the beetle preferentially resided in the refuse pits. Next, it was shown that the beetles readily consumed seeds and flour, whereas other food sources were poorly accepted and ant brood was never even eaten. The beetles did not elicit a strong aggression response in Messor ants, and they could tolerate very high densities of workers without clear costs. The beetles modestly mimicked the nest recognition cues of their Messor host. This imperfect mimicry could promote the adoption of the beetle in the ant colony, in concert with mechanical defence generated by its tank-like body. Isolation of the beetle from its host did not significantly affect the beetle's chemical cuticular profile nor did it provoke elevated ant aggression, indicating that the beetle does not acquire the chemicals passively from its host.

4. This paper discusses the fact that waste dumps in social insect nests are hotspots for arthropod symbionts. It shows that symbionts in this niche may employ behavioural, trophic and chemical strategies that are different from those found in other niches of social insect nests.
\end{abstract}

Key words. Ant guest, chemical mimicry, commensalism, hydrocarbon, inquiline, myrmecophily.

\section{Introduction}

It is widely supported that niche diversity, resource availability, and ecosystem stability have a strong positive effect on species diversity and maintenance in large-scale ecosystems (Chesson, 2000; Fine, 2015). These factors are also proposed as primary determinants of diversity in natural microcosm ecosystems,

Correspondence: Thomas Parmentier, Terrestrial Ecology Unit (TEREC), Department of Biology, Ghent University, K.L. Ledeganckstraat 35, 9000, Ghent, Belgium. E-mail: thomas.parmentier@ugent.be as shown in aquatic microcosm communities of rock pools (Brendonck et al., 2015), bromeliads (Richardson, 1999; Armbruster et al., 2002), and pitcher plants (Krieger \& Kourtev, 2012). Terrestrial natural microcosms with an astonishing high diversity of arthropods can be found in the nests of social insects (Wilson, 1971; Kistner, 1979; Hölldobler \& Wilson, 1990). Social insect associates are attracted to the nest by a constant supply of resources and the relatively stable, homeostatic conditions (Rosengren et al., 1987). There is a tendency for social insects with larger nests and a higher variety of nest niches to attract a more diverse fauna of inquiline arthropods (Hughes 
et al., 2008; Kronauer \& Pierce, 2011; Cristaldo et al., 2012). Within nests of social insects, one can discern different types of niches which attract other groups of inquilines. So far, most research has focused on inquilines living in the central brood chambers of social insect nests. This niche is mostly occupied by very specialised parasites that feed on the valuable brood. A classic example are the caterpillars of Maculinea butterflies, which are treated as true nest mates (no aggression, groomed, fed and transported) by their Myrmica host workers (Nash et al., 2008). The body of host workers is another niche occupied by many symbionts. Some, such as the notorious Varroa mites, live as ectoparasites on the body surface, whereas endoparasites live inside the host body (Lachaud \& Pérez-Lachaud, 2015). The body niche may be even compartmentalised in multiple 'subniches' when the ectoparasites have adapted to different body parts (Rettenmeyer et al., 2011). Nest chambers with food storage are also colonised by inquilines, as exemplified by the arthropods living in fungus gardens of termites and leaf-cutter ants (Kistner, 1982; Nehring et al., 2016). Another major niche that is occupied by many symbionts is found in the waste dumps or refuse piles in and around the nest entrances. These dumps are especially formed by species that produce excessive loads of waste (Bot et al., 2001; Hart, 2002). Coordinated waste disposal is a part of an intricate waste management system and helps to reduce the spread of pathogens (Bot et al., 2001).

The type of preferred niche is tightly linked with the behavioural, chemical, and trophic strategies employed by the symbionts. Inquilines living in the dense brood chambers are typically fully integrated into the colony and do not provoke aggression (but see Thiasophila angulata in Parmentier et al., 2018). They stay undetected by mimicking the blend of cuticular hydrocarbons (CHCs) of their host, which act as the nest recognition cues in social insects (van Zweden \& d'Ettorre, 2010). These species mostly feed on brood or may be fed by the workers that regurgitate liquid food (trophallaxis) (Hölldobler \& Wilson, 1990). Symbionts occupying niches with lower densities of workers, such as the peripheral chambers or waste dumps, tend to be less specialised and provoke aggression to different degrees. These symbionts do not generally employ chemical deception, but rather capitalise on general defence strategies such as chemical repellency, hiding behaviour, swift movements and defensive, armoured bodies (Kistner, 1979; Parmentier et al., 2017a). They mainly scavenge on decaying food remains, dead workers, fungi, and organic material, but may feed on other inquilines as well (Parmentier et al., 2016a).

A unique niche in ant nests is the waste dump (chaff or refuse pile) of seed harvester ant species. Granivory is a strategy that evolved in many ant lines (Hölldobler \& Wilson, 1990; Johnson, 2001) and has been perfected in species found in the genera Messor and Pogonomyrmex. Granivorous specialists primarily feed on collected seeds in the nest and the workers may have specific adaptations such as a psammophore (structure under the head to hold seeds) or a major worker caste with very big heads specialised in seed milling (Hölldobler \& Wilson, 1990). Seed harvester ants typically store seeds in chambers in the nest and have a profound effect on the dynamics and vegetation of dry grasslands and semi-arid environments (Johnson, 2001). Granivory generates large amounts of waste, such as seed parts, fruits, husks, spikes, and organic debris which are carefully disposed of in superficial chambers and around the nest openings (Hölldobler \& Wilson, 1990; Steinberger et al., 1991). The nests of seed-harvesting ants attract a diverse, yet understudied, fauna of ant inquilines or myrmecophiles (Lavigne, 1969; Cushing, 1998; Uppstrom \& Klompen, 2011; Molero-Baltanás et al., 2017), which is probably promoted by the presence of the garbage dumps. Previously, it has been reported that the beetle Araeoschizus is specifically associated with the waste chambers of Pogonomyrmex harvester ants (Lavigne, 1969; Clark \& Blom, 1988).

The strategies of inquilines living in the brood chambers of social insects are much better explored (Hölldobler, 1967; Cammaerts, 1995; Akino \& Knapp, 1999; Di Giulio et al., 2015) than those of other niches. It would be useful to broaden our knowledge on the adaptations and strategies of social insect associates that colonise non-brood associated niches such as waste dumps. An apparently unspecialised beetle is the obligate myrmecophile Oochrotus unicolor Lucas, 1852, a darkling beetle (Tenebrionidae) with reduced eyes and associated with Messor seed harvester ants (Wasmann, 1894; Donisthorpe, 1927a; Soldati \& Soldati, 2000). Our aim was to demonstrate that this peculiar beetle is adapted to the unique seed waste dump niche of its granivorous host. Therefore we examine the niche preference of this species and link this with its behavioural, chemical (CHCs), and trophic strategies.

\section{Materials and methods}

Study species and sampling

Messor barbarus (Linnaeus, 1767) is a common ant in southern Europe (Cerdan, 1989; Seifert, 2007). It is a granivorous specialist which forages in dense trails for seeds. The seeds are stored in granaries and subsequently consumed in the nest. The waste is disposed of near the nest openings, but also superficial chambers may be partly filled (R. Molero-Baltanás \& T. Parmentier, pers. obs.; Hölldobler \& Wilson, 1990). The worker caste is strongly polymorphic and the major caste often has brownish heads (Fig. 1a) (Seifert, 2007). We typically found M. barbarus nests by lifting large stones. We did not excavate the whole nest, but rather scanned the exposed galleries and chambers for the associated $O$. unicolor beetles. Chaff and debris were regularly found in the galleries under the stones (Fig. 1b). The ant workers and beetles were collected using an aspirator and stored with nest material in plastic containers with a moist plaster bottom. The glass recipient of the aspirator was regularly cleaned with hexane to avoid cross-contamination of chemical cues. We collected Oochrotus beetles in five M. barbarus nests over the course of April and May 2019. Two nests with beetles were found in the south of Spain $\left(\mathrm{C} 1,38^{\circ} 35^{\prime} 55.27^{\prime \prime} \mathrm{N}, 4^{\circ} 55^{\prime} 0.25^{\prime \prime} \mathrm{W}\right.$ in the Sierra Morena mountains, to the north of Córdoba; and $\mathrm{C} 2$, $37^{\circ} 52^{\prime} 24.56^{\prime \prime} \mathrm{N}, 4^{\circ} 50^{\prime} 8.06^{\prime \prime} \mathrm{W}$, near Córdoba) and three nests with beetles were found near Perpignan, in the south of

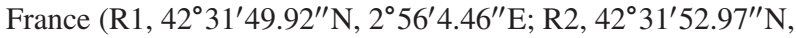
$2^{\circ} 55^{\prime} 56.66^{\prime \prime} \mathrm{E}$; R3, $\left.42^{\circ} 31^{\prime} 48.62^{\prime \prime} \mathrm{N}, 2^{\circ} 56^{\prime} 7.58^{\prime \prime} \mathrm{E}\right)$. We kept the collected beetles with workers (minimum 200 workers), nest material, and brood of the host colony in separate artificial nests 
(container, $8.5 \mathrm{~cm}$ diameter, height $13.5 \mathrm{~cm}$, with Fluon coating) in the laboratory. We provided sugar water (30\%) and flour $\mathrm{ad}$ libitum. Beetles and workers of nest C2 and R3 were directly stored in glass vials at $-21^{\circ} \mathrm{C}$.

In addition to the five nests in which we collected beetles, we also scanned 32 other M. barbarus nests in the Córdoba area to assess the distribution and densities of the beetles. To do so, we used three methodologies: (i) digging up nests; (ii) analysing nest material using a Berlese-Tullgrem funnel; and (iii) lifting stones covering the nests.

\section{Experiment 1: Nest localisation preference}

To test whether the beetles were attracted to the refuse piles in Messor nests, we crafted an artificial laboratory nest composed of six round plastic pots (diameter bottom $4.5 \mathrm{~cm}$, height $7 \mathrm{~cm}$ ). The pots were connected with plastic tubes (length $1 \mathrm{~cm}$, inner diameter $1 \mathrm{~cm}$ ) in such a way that every pot was connected with two other pots (cf. setup in Parmentier et al., 2016b; Fig. 1d). The pots and tubes were filled with a layer of plaster of Paris to keep the nest moist. The upper part of the pots was coated with Fluon to prevent the ants and beetles from escaping. In five pots we added $12 \mathrm{ml}$ of sandy soil in which the Messor nests were dug out. In one pot we spread $12 \mathrm{ml}$ of organic material collected in refuse pits of the Messor nests. We added between 250 and 360 workers of M. barbarus, c. 50 larvae and egg piles, and a variable number of Oochrotus beetles in the different replicates. Ants, nest material, and beetles of nests R1 and R2 were each used in two replicates, resulting in a total of four replicates. Different beetles were tested in every replicate (replicate 1 of R1, $N=18$; replicate 2 of R1, $N=21$; replicate 1 of R2, $N=16$; replicate 2 of R2, $N=13$ ), ants (R1, 360 workers; R2, 250 workers) and brood were reused. In one pot (nest chamber) we laid a small piece of plaster on the soil material to stimulate the workers to store their brood underneath (Fig. 1d). We aimed to have a nest with one chamber with all the brood, four peripheral chambers, and one chamber with the refuse material. The pots were closed with a lid with some pinholes and stored in complete darkness. After $48 \mathrm{~h}$, we sealed the nest chambers with a cotton plug and sieved the nest material of the different chambers in a large tray. All introduced beetles were still alive after $48 \mathrm{~h}$.

For each of the four replicates, we ran a two-sided exact binomial test to determine whether the number of beetles in the refuse chamber deviated from 1/6. When the beetles were attracted to the refuse chamber, we expected in a six-chamber nest that more than one-sixth of the tested beetles would be found in this refuse chamber.

\section{Experiment 2: Trophic ecology of Oochrotus}

By offering different potential food sources present in a Messor nest to the beetles, we aimed to infer the feeding preferences of this beetle. Beetles were starved for 1 day before a trial. Beetles were then individually housed in small Petri dishes (diameter $5 \mathrm{~cm}$ ) with a moistened plaster bottom. We added charcoal to the plaster to increase the visual contrast with the food sources. Next, one of the following food sources was added: slightly crushed grass seed (four to six), fresh yeast (g), flour (g), a cut maggot of Phaenicia sericata, a small $M$. barbarus larva, a M. barbarus egg, and a dead M. barbarus worker. We recorded the behaviour of the tested beetle under red light for $1 \mathrm{~h}$. A food item was accepted if we observed the beetle licking, dragging, or biting it for at least $30 \mathrm{~s}$. Petri dishes with ant larvae and ant eggs were left in darkness for $24 \mathrm{~h}$ and then checked for consumption by the beetles. Replicates of a food source were tested with unique beetles from nest $\mathrm{C} 1$ and R3. Some beetles were used again in trials with another food source, but this was again preceded by a starvation period of 1 day. Some myrmecophiles may steal a food droplet from their host by engaging in trophallaxis (Hölldobler \& Wilson, 1990; Cammaerts, 1995). We did not test this feeding strategy for $O$. unicolor, because trophallaxis between $M$. barbarus workers was never observed.

\section{Experiment 3: Behavioural interactions between ant and beetle}

Aggression of M. barbarus and other ant species towards the beetle. We scored the aggression response of different ant species towards the beetle. We hypothesised that non-host ants would behave much more aggressively towards the beetle than the preferred Messor host. The following ant species were tested: M. barbarus, Aphaenogaster senilis, Camponotus micans, Pheidole pallidula, Camponotus cruentatus, Lasius niger, Myrmica rubra and Tapinoma nigerrimum. The tested non-host ant species have an overlapping distribution range with the beetle (AntWiki, 2019), but were also collected in locations where the beetle does not occur: A. senilis, C. micans, and $P$. pallidula near Córdoba (Spain); $C$. cruentatus near Montpelier (France); and L. niger, M. rubra, and T. nigerrimum in the north of Belgium. We added 10 workers of a species to an arena (plastic cup: diameter $7 \mathrm{~cm}$, height $5 \mathrm{~cm}$ ) with a plaster bottom and Fluon-coated wall and let them acclimatise for $30 \mathrm{~min}$. We selected medium-sized workers in species with worker polymorphism. Next, we introduced a beetle and after $30 \mathrm{~s}$, we scored 20 consecutive interactions. An interaction was defined as an encounter in which the antenna of an ant crossed the body of a beetle. Ants displayed non-aggressive interactions, such as ignoring and inspecting, and aggressive interactions, such as biting, mandible opening and chasing. Ant aggression was quantified as the proportion of aggressive interactions (biting, mandible opening, chasing) out of the 20 interactions. We replicated aggression trials for each ant species with 10 different beetles (origin nest R1). Beetles were reused for different ant species, but there was a latency between the trials of at least $1 \mathrm{~h}$. For M. barbarus, we conducted more aggression trials and in different host colonies. We determined aggression in three colonies (from nest R1, R2 and C1) towards beetles found in the same nest. Beetles were retested in the aggression trials with $M$. barbarus between one and three times, but with different sets of workers of the host colony in the replicas.

We compared proportions of aggressive interactions towards the beetle across the tested ant species with a generalised linear mixed model (GLMM) and a binomial response. Ant species was fitted as an independent variable and beetle identity and colony (multiple colonies tested in M. barbarus; in 

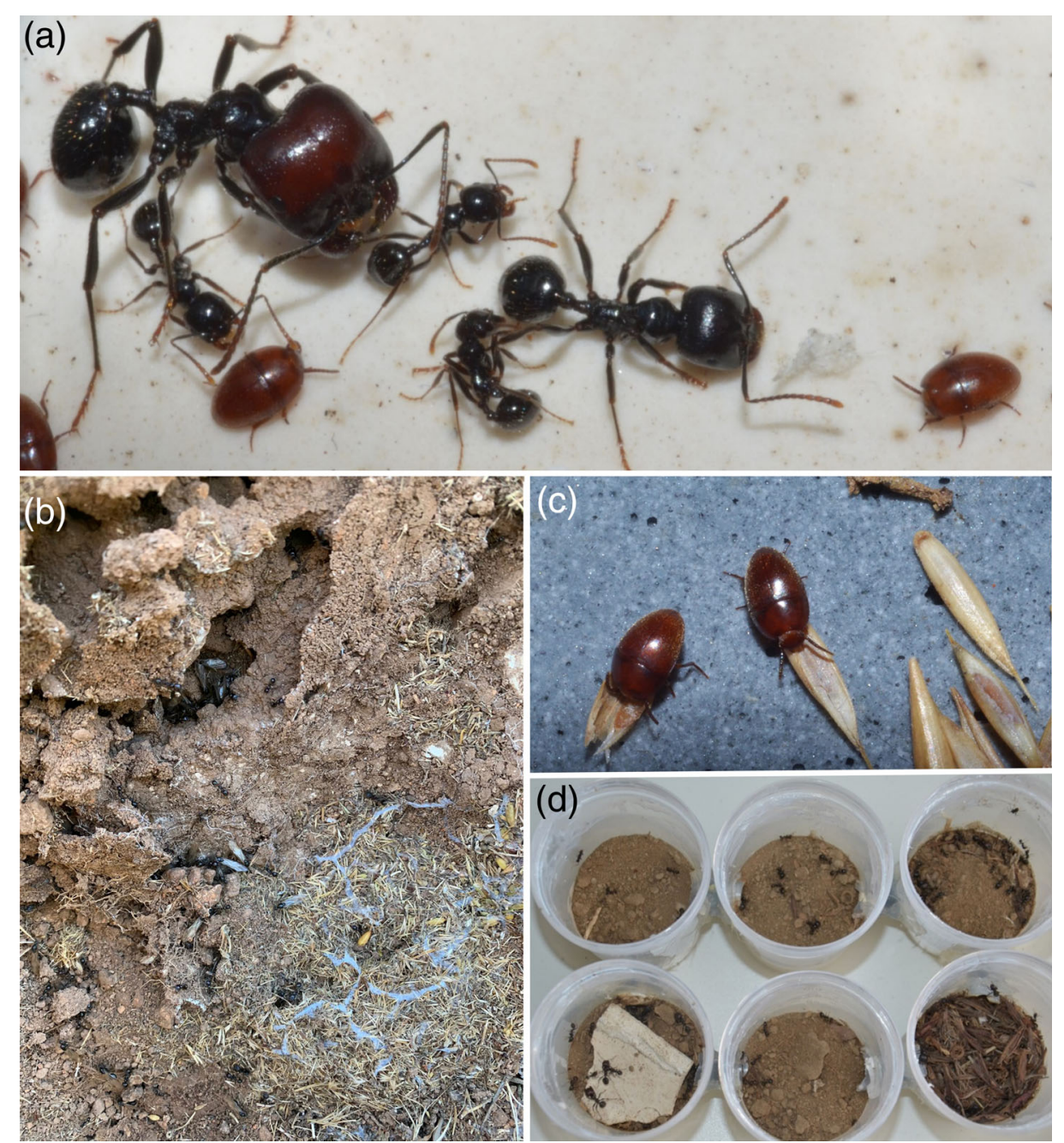

Fig. 1. Overview of the association between Messor barbarus and Oochrotus unicolor. (a) Polymorphic worker caste of M. barbarus interacting with $O$. unicolor. (b) A typical waste dump of seed and organic material (chaff or refuge pile) of a $M$. barbarus nest. The silk tubes on the pile are created by Embioptera. (c) Oochrotus unicolor feeding on grass seeds. (d) Experimental laboratory nest to test the niche preference of $O$. unicolor. The chamber in the lower left corner is the brood chamber. Brood and most of the M. barbarus workers are hidden under the piece of plaster. The chamber with material from the waste dump is in the lower right corner. The other four chambers are the peripheral chambers. [Colour figure can be viewed at wileyonlinelibrary.com].

other ant species we used a single colony) as random factors [model: proportion aggression $=$ ant species $+(1 \mathrm{lbeetle}$ identity $)+(1$ lcolony $)$, family = binomial $]$. The binomial model was not overdispersed and residuals were examined to confirm model fit. The aggression response of ant species was pairwise compared with Tukey post hoc tests. The $95 \%$ confidence intervals of the estimates were calculated with the R function 'confint' with the Wald method in the LME4 package.

Survival of the beetle in a crowded M. barbarus nest chamber. We housed $100 \mathrm{M}$. barbarus workers, including all size classes, in a small plastic pot (diameter $5 \mathrm{~cm}$, height $5.5 \mathrm{~cm}$ ) with a moistened plaster bottom. The wall was coated with Fluon and some pinholes were bored in the lid. Next we added 10 beetles found in the same nest of the workers to the pot (Fig. S1). We placed the pot in darkness and counted the number of beetles after 3 days. As a control, we checked survival after 3 days of 10 beetles in a similar set-up without ants. We replicated both the treatment with ants as the control three times (twice with workers and beetles from R1 and once with individuals from $\mathrm{R} 2)$. We used different beetles in all trials.

As the sample sizes were too low for statistical significance testing, we analysed the data descriptively.

\section{Experiment 4: Chemical ecology of Oochrotus}

Cuticular hydrocarbon profile of M. barbarus and associated beetles. We analysed the hydrocarbon profile of beetles and ants originating from four different nests. Beetles and $M$. barbarus ants were either directly collected from the 
nest in the field (C2 and R3) or were taken with clean forceps from the laboratory nests. They were transferred to 2-ml glass vials capped with a polytetrafluoroethylene 188 septum (Sigma-Aldrich, St. Louis, Missouri). They were subsequently killed by freezing and individually stored at $-21^{\circ} \mathrm{C}$. The hydrocarbons were then extracted by adding $100 \mu \mathrm{l}$ of hexane to these vials. We removed the insects after $10 \mathrm{~min}$ and let the hexane evaporate at room temperature under a laminar flow hood. Before the analysis, we diluted beetle and ant samples again in $30 \mu \mathrm{l}$ of hexane. We analysed $2 \mu \mathrm{l}$ of each hexane extract on a gas chromatography (Thermo GC - Trace 1300 series, Waltham, Massachusetts) and mass spectrometry (Thermo ISQ series, $-70 \mathrm{eV}$, electron impact ionisation) equipped with a Restek (Bellefonte, Pennsylvania)RXi-5sil MS column $(20 \mathrm{~m} \times 0.18 \mathrm{~mm} \times 0.18 \mu \mathrm{m})$. Samples were injected in the splitless mode with an inlet temperature of $290^{\circ} \mathrm{C}$ and with helium as a carrier gas at a flow rate of $0.9 \mathrm{ml} \mathrm{min}^{-1}$. The oven was held for $1 \mathrm{~min}$ at $40^{\circ} \mathrm{C}$, then programmed from 40 to $200^{\circ} \mathrm{C}$ at $20^{\circ} \mathrm{C} \mathrm{min}{ }^{-1}$ and from 200 to $340{ }^{\circ} \mathrm{C}$ at $8{ }^{\circ} \mathrm{C}$ $\mathrm{min}^{-1}$. The final temperature of $340^{\circ} \mathrm{C}$ was held for $4 \mathrm{~min}$. The order in which the samples were run was randomised. We also ran a linear C9 to C40 alkane ladder standard (49452-U; Sigma-Aldrich) at three different concentrations (0.001, 0.01 . and $0.1 \mu \mathrm{g} \mathrm{ml}^{-1}$ ) before and directly after the insect samples. Absolute quantification (to determine the total amount produced in ng per individual) was performed using interpolation on a $\log -\log$ scale (the relationship between peak area and concentration is linear on a $\log -\log$ scale; Parmentier et al., 2017a), based on the peak areas of the closest eluting n-alkane of our external alkane ladders for each peak. Retention indices of all peaks were calculated using cubic spline interpolation (Messadi et al., 1990) based on the elution times of the external alkane ladders. The calculated retention indices and the mass spectrometric fragmentation patterns enabled us to identify the CHCs.

We compared the composition of the $\mathrm{CHC}$ peaks that were present in both the ants and beetles $\left(\mathrm{CHCs}_{O-M}, \mathrm{~N}=17\right)$. The mass of each hydrocarbon peak was standardised relative to the total mass of $\mathrm{CHCs}_{O-M}$ present in the sample. These proportional $\mathrm{CHCs}_{O-M}$ values were then transformed using the Aitchison transformation (Aitchison, 1986) after which they were visualised with a non-metric multidimensional scaling (NMDS, two-dimensional, Euclidean distance matrix). The analysis was conducted in $\mathrm{R}$ (v.3.4.2) using the package VEGAN. To assess nest differences in $\mathrm{CHC}$ composition in more detail, we conducted similar transformations and analyses on a subset with the ant samples and one with the beetle samples. Here we started with all hydrocarbons detected in $M$. barbarus $\left(\mathrm{CHCs}_{M}, N=28\right)$ and O. unicolor $\left(\mathrm{CHCs}_{O}, N=23\right)$, respectively. To test differences in $\mathrm{CHC}$ composition between ants and beetles, we conducted a PERMANOVA based on a matrix of pairwise Euclidean distances of the Aitchison-transformed $\mathrm{CHCs}_{O-M}$ values ('adonis' function in R package VEGAN, 999 permutations). We specified nest origin as a stratum, so that permutations were only allowed within profiles of beetles and ants of the same nest. Nest-specific expression of CHCs in the ants and beetles were tested on the Euclidean distance matrix of the Aitchison-transformed $\mathrm{CHCs}_{M}$ and $\mathrm{CHCs}_{O}$, respectively.
Aggression of M. barbarus towards beetles collected in alien M. barbarus colonies. We compared the aggression response of 10 workers of R2 towards beetles found in the nest R2 (= associated beetles, $N=10$ ) and beetles found in the nest C1 (= alien beetles, $N=10$ ). Workers of $\mathrm{C} 1$ and $\mathrm{R} 2$ were highly aggressive towards each other. The setup and procedure of the aggression tests were similar to these described earlier, but observations were blind with respect to the nest origin of the beetle. The aggression towards each beetle was retested in three trials with different sets of host workers $(3 \times 10$ trials for both associated and alien beetles in total). We used medium-sized workers.

We ran a GLMM with a binomial distribution to compare the proportion of aggressive interactions towards associated and alien beetles. Beetle origin (associated versus alien) was the predictor, beetle identity was included as a random factor. We also added an observation-level random factor to account for overdispersion (Browne et al., 2005) [model: proportion aggression $=$ beetle origin $+(1$ lbeetle id $)+(1$ lobservation $)$, family $=$ binomial $]$. Residuals were examined to confirm model fit.

Effect of beetle isolation on its CHC profile and host ant aggression. We isolated beetles without ants in a pot similar to the pot containing the laboratory nest, but without ants and nest material. Beetles were given flour ad libitum and an Eppendorf tube stuffed with moist cotton. We prepared one pot with beetles isolated from nest $\mathrm{C} 1(N=7)$ and one for those isolated from R1 $(N=5)$. After 11 days, we subjected beetles from a laboratory nest (C1 or R1) and isolated beetles from the same laboratory nest to aggression tests with 10 host workers as described earlier, but the observations were blind with respect to the treatment (isolated versus ant-associated). Aggression towards each beetle was retested in three trials with different sets of host workers. We used medium-sized workers. After the aggression tests we stored the beetles in the freezer at $-21^{\circ} \mathrm{C}$ pending $\mathrm{CHC}$ extraction and $\mathrm{CHC}$ analysis as described earlier. Differences in $\mathrm{CHC}$ composition between associated and isolated beetles originating from $\mathrm{R} 1$ and $\mathrm{C} 1$ were also tested using a PERMANOVA based on a matrix of pairwise Euclidean distances of the Aitchison-transformed $\mathrm{CHCs}_{O}$ values and nest origin as a stratum,

We ran a GLMM with a binomial distribution to compare the proportion of aggressive interactions towards associated and isolated beetles. Beetle origin (associated versus isolated) was the predictor, and beetle identity and host colony (from nest $\mathrm{R} 1$ or $\mathrm{C} 1$ ) were included as random factors. We also added an observation-level random factor to account for overdispersion (Browne et al., 2005) [model: proportion aggression = beetle origin $+(1$ lhost colony $)+(1$ lbeetle id $)+(1$ lobservation $)$, family = binomial]. Residuals were examined to confirm model fit.

\section{Results}

The beetles can reach high densities in Messor nests. We collected a maximum number of $N_{\mathrm{R} 1}=52$ beetles in nest R1 (beetles collected in other nests: $N_{\mathrm{R} 2}=38, N_{\mathrm{R} 3}=3, N_{\mathrm{C} 1}=44$, $N_{\mathrm{C} 2}=6$ ). We found the beetle in a large fraction of the $M$. 
Table 1. Distribution of Oochrotus unicolor in Messor barbarus nests in the Córdoba region.

\begin{tabular}{lll}
\hline & $\begin{array}{l}\text { Nests with beetles/ } \\
\text { nests sampled }\end{array}$ & Abundances \\
\hline Digging & $4 / 6$ & $3,7,12,15$ \\
Berlese-Tullgrem & $3 / 4$ & $11,12,14$ \\
Lifting the covering stone & $5 / 22$ & $1,2,3,7,19$ \\
\hline
\end{tabular}

Table 2. Distribution of beetles over the six nest chambers in the nest localisation experiment.

\begin{tabular}{|c|c|c|c|c|}
\hline Nest/replicate & $\begin{array}{l}\text { Refuse } \\
\text { chamber }\end{array}$ & $\begin{array}{l}\text { Brood } \\
\text { chamber }\end{array}$ & $\begin{array}{l}\text { Peripheral } \\
\text { nest } \\
\text { chambers } \\
\text { (summed } \\
\text { over four } \\
\text { chambers) }\end{array}$ & $\begin{array}{l}\text { Total } \\
\text { no. of } \\
\text { beetles }\end{array}$ \\
\hline Nest R1: replicate 1 & $9(P=0.001)$ & 2 & 7 & 18 \\
\hline Nest R1: replicate 2 & $10(P<0.001)$ & 3 & 8 & 21 \\
\hline Nest R3: replicate 1 & $14(P<0.001)$ & 2 & 0 & 16 \\
\hline Nest R3: replicate 2 & $7(P=0.002)$ & 1 & 5 & 13 \\
\hline
\end{tabular}

barbarus nests (12 out of 32 nests) in the Córdoba region (Table 1).

\section{Experiment 1: Nest localisation preference}

The beetles were strongly attracted to the waste chambers with organic material in all four replicates (exact binomial tests, $P$-values ranging from $<0.001$ to 0.002 ; Table 2 ). These chambers housed a moderate number of workers of the laboratory nest $[9.9 \pm 4.1 \%$ (SD) of the workers]. The majority of the workers and all the brood were always found in the brood chamber $(73.5 \pm 8.0 \%$ of the workers); the remaining $16.5 \pm 6.2 \%$ of the workers were distributed over the four peripheral chambers. Although there was a clear preference for the waste chambers, beetles were also found to a lesser degree in the very crowded brood chambers and peripheral chambers (Table 2).

\section{Experiment 2: Trophic ecology of Oochrotus}

The beetles readily fed on grass seeds (Fig. 1c; Video S1). In 14 out of the 16 trials we observed seed consumption. We also observed that the beetles carried the seeds away, and we recorded contests for seeds with other beetles (Video S1). Flour derived from wheat seeds was also readily accepted in most trials (12 out of 16). We also observed that the beetles in the laboratory nests fed on flour within minutes. Half of the tested beetles (8/16) preyed on a dead maggot. Yeast consumption was only observed in one out of 16 trials. The beetles did not act as brood predators (egg consumption, 0/5 trials; larva consumption, 0/12 trials), and eggs and larvae were not damaged. Dead ants were also ignored (0/11).

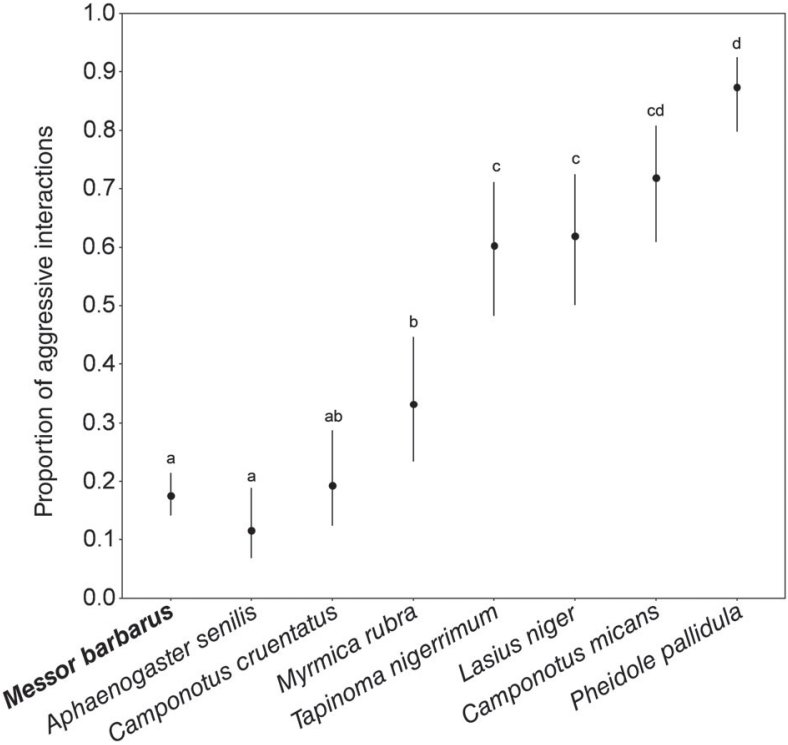

Fig. 2. Proportion of aggressive interactions $( \pm 95 \% \mathrm{CI})$ by different species of ants towards Oochrotus unicolor. Species with no letters in common are significantly different at the $\alpha=0.05$ level (generalised linear mixed model followed by Tukey post hoc tests).

Experiment 3: Aggression of M. barbarus and other ant species towards Oochrotus

Aggression towards $O$. unicolor was tested in different ant species. Colonies of $M$. barbarus displayed mild aggression (proportion of aggression $=0.17,95 \%$ CI: $0.14-0.21$ ) towards beetles found in the same nest (Video S2). The beetles were ignored in most of the encounters. Beetles were never killed or wounded during the aggression trials. When the ants tried to bite, the beetles either ran away or ducked down to the substrate (Video S2). The ants were not able to grab the beetle, because of its rounded body. Other ant species showed a variable degree of aggression towards $O$. unicolor (Tukey post hoc differences GLMM; see letter codes in Fig. 2). Aphaenogaster senilis and $C$. cruentatus were also very tolerant towards the beetle (Fig. 2), whereas $P$. pallidula and $T$. nigerrimum were very hostile and grabbed the legs of the beetle directly.

Survival of the beetle was only tested with $M$. barbarus. Confining the beetles to a nest chamber with a very high density of Messor workers did not affect their survival in the short term. After 3 days, all beetles were still alive ( 30 beetles summed over three replicates), showed normal behaviour and lacked apparent injuries. No beetle mortalities ( 30 beetles summed over three replicates) were detected in the control setup without ants.

\section{Experiment 4: Chemical ecology of Oochrotus}

The cuticular profiles of $O$. unicolor and $M$. barbarus shared $17 \mathrm{CHC}$ peaks. Six $\mathrm{CHC}$ peaks were unique to $O$. unicolor, and 11 CHC peaks to M. barbarus (Fig. 3; Table 3). In addition, seven non-CHC peaks were also detected in $M$. barbarus. Note that some of the peaks found in only 


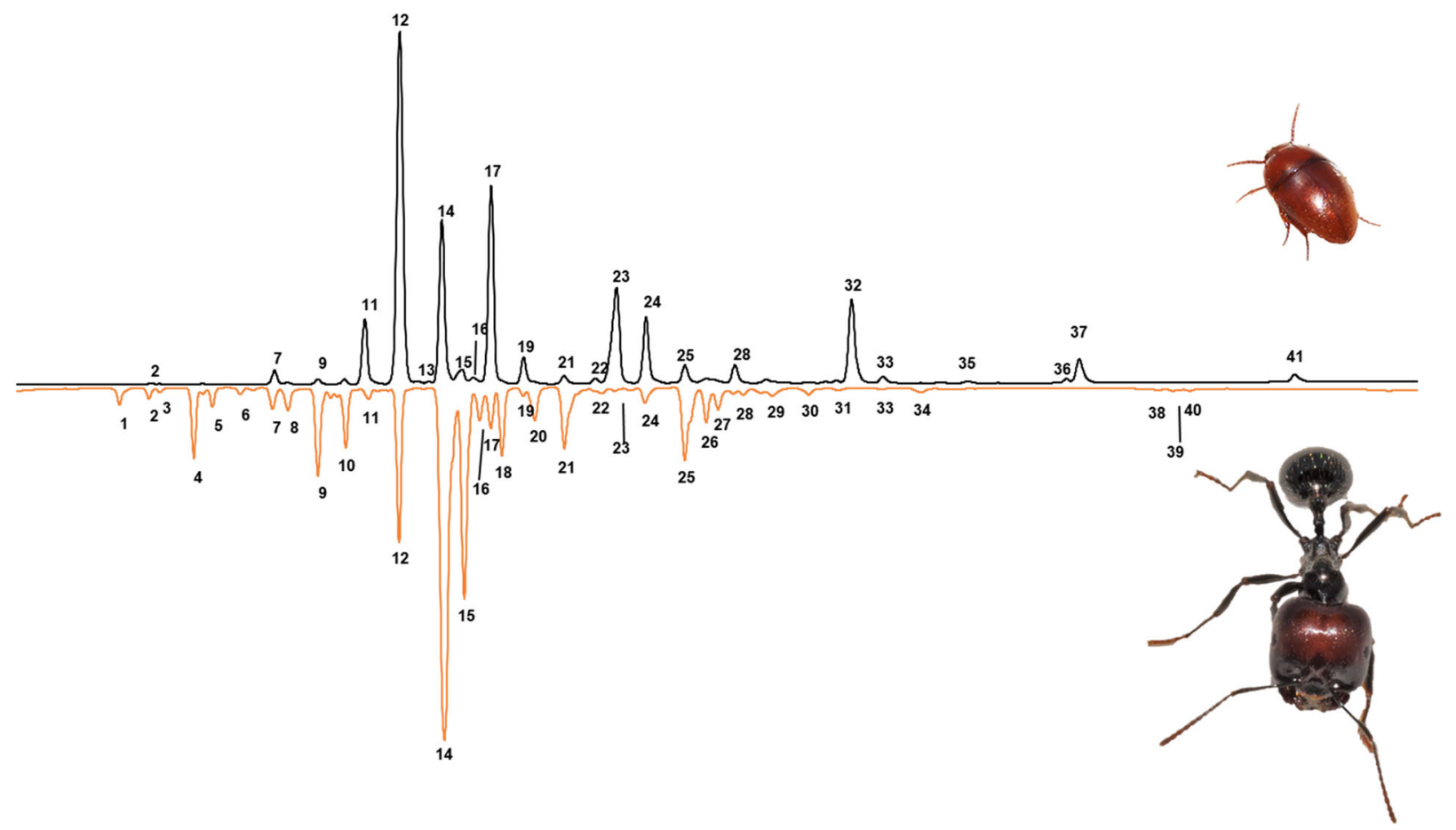

Fig. 3. Representative cuticular chromatograms of Oochrotus unicolor and its host Messor barbarus. Peak identities can be found in Table 2. [Colour figure can be viewed at wileyonlinelibrary.com].

one species might be under the detection threshold in the other species, resulting in an underestimation of the amount of peaks shared. The peaks corresponding with $\mathrm{n}-\mathrm{C} 25$ and $7,9,11,13-\mathrm{MeC} 25$ were dominant in both species. 5-MeC25 was much more important in Messor, whereas 3-MeC25 was much more prominent in Oochrotus. The profiles of the beetles were clearly separated from their host M. barbarus workers (PERMAnOVA, $R^{2}=0.66, P=0.001$; Fig. 4). Ants distinctly grouped per nest/colony (PERMANOva, $R^{2}=0.70, P=0.001$ ). Beetles found in the same host nest/colony tend to group (PERMANOVA, $R^{2}=0.23, P=0.002$ ), but the clustering was less clear than in host workers. This is reflected in the much lower explained variation by 'colony origin' in the latter model $\left(R^{2}=0.23\right.$ vs 0.70$)$. Ant workers of nest $R^{2}$ were not more aggressive towards alien beetles (proportion aggression $=0.11$, 95\% CI: $0.08-0.16)$ than towards associated beetles (proportion aggression $=0.13,95 \% \mathrm{CI}: 0.09-0.17)\left(\mathrm{GLMM}, \chi^{2}=0.31\right.$, d.f. $=1, P=0.58)$. The profiles of beetles isolated for 11 days changed slightly (PERMANOVA, $R^{2}=0.13, P=0.002$ ), but still overlapped with the profiles found in this beetle. Aggression of workers towards 11-day-isolated beetles (proportion aggression $=0.27,95 \%$ CI: $0.23-0.32)$ was not higher than aggression towards associated beetles (proportion aggression $=0.26,95 \%$ CI: 0.22-0.31) (GLMM, $\chi^{2}=0.93$, d.f. $\left.=1, P=0.34\right)$.

\section{Discussion}

We demonstrate that the darkling beetle $O$. unicolor preferentially lives in the waste dumps or chaff piles of Messor seed harvester ants. This distinct niche contains an accumulation of seeds, debris and organic plant material (Cerdan, 1989; Steinberger et al., 1991). The dietary preferences of these beetles are clearly adapted to this niche. Seeds were readily accepted and even dragged away. Granivory in social insect guests is probably rare, but was suggested in the tenebrionid beetle Araeoschizus associated with Pogonomyrmex harvester ants (Lavigne, 1969). Oochrotus unicolor also fed on dead prey remnants. This food type, however, is much less common in Messor ants, as seeds are their main food source (Cerdan, 1989; Cerdá \& Retanam, 1994). Interestingly, the beetle did not feed on ant brood, whereas many unspecialised myrmecophiles will consume ant larvae or eggs when offered (von Beeren et al., 2010; Parmentier et al., 2016a). The diet of non-ant-associated relatives of the beetle is unknown, but granivory has evolved multiple times in the beetle family Tenebrionidae (Allsopp, 1980; Kistner, 1982). Overall, O. unicolor appears to impose low fitness costs on its host colony and may be regarded as a commensal. The feeding on seed debris may even reduce the loads of pathogens by which the beetle could provide mutualistic cleaning services to its host (cf. Biani et al., 2009).

The diversity of symbionts of Messor ants has been largely overlooked. Although previous studies (Sánchez-Piñero \& Gómez, 1995; Molero-Baltanás et al., 1998; Uppstrom \& Klompen, 2011; Molero-Baltanás et al., 2017) and our observations of the sampled nests hint that a very diverse group, including mites, beetles, silverfish, crustaceans, spiders, and other groups of arthropods, makes a living in the nests of these ants, especially in the seed waste dumps (chaff piles) (Fig. S2). Many of them are facultative associates, meaning 
Table 3. Comparison of cuticular components of Messor barbarus $(N=18)$ and Oochrotus unicolor $(N=31$, based on all individuals displayed in Fig. 3, except for the isolated individuals).

\begin{tabular}{|c|c|c|c|c|}
\hline \multirow[b]{2}{*}{$\mathrm{Nr}$. } & \multirow[b]{2}{*}{ RI } & \multirow[b]{2}{*}{ Compounds } & \multicolumn{2}{|c|}{$\begin{array}{l}\text { Abundance in cuticular } \\
\text { profile }(\%, \text { mean } \pm \text { SD })\end{array}$} \\
\hline & & & M. barbarus & O. unicolor \\
\hline 1 & 2275 & $\mathrm{C} 23: 1$ & $1.2 \pm 1.0$ & \\
\hline 2 & 2299 & $\mathrm{n}-\mathrm{C} 23$ & $0.7 \pm 0.4$ & $0.1 \pm 0.1$ \\
\hline 3 & 2308 & Non-CHC & $0.4 \pm 0.4$ & \\
\hline 4 & 2335 & 9,11-MeC23 & $3.1 \pm 1.0$ & \\
\hline 5 & 2349 & $5-\mathrm{MeC} 23$ & $0.9 \pm 0.3$ & \\
\hline 6 & 2372 & 3-MeC23 & $0.4 \pm 0.2$ & \\
\hline 7 & 2400 & $\mathrm{n}-\mathrm{C} 24$ & $1.5 \pm 1.6$ & $1.2 \pm 1.0$ \\
\hline 8 & 2410 & Non-CHC & $1.6 \pm 2.2$ & \\
\hline 9 & 2434 & $\mathrm{MeC} 24$ & $4.2 \pm 1.4$ & $0.5 \pm 0.8$ \\
\hline 10 & 2457 & Non-CHC & $3.0 \pm 3.5$ & \\
\hline 11 & 2473 & $\mathrm{C} 25: 1$ & $1.1 \pm 0.5$ & $4.0 \pm 2.3$ \\
\hline 12 & 2500 & $\mathrm{n}-\mathrm{C} 25$ & $10.4 \pm 5.1$ & $26.8 \pm 7.7$ \\
\hline 13 & 2525 & Unidentified $\mathrm{CHC}$ & & $0.2 \pm 0.1$ \\
\hline 14 & 2535 & 7,9,11,13-МeC25 & $22.7 \pm 5.4$ & $11.9 \pm 3.9$ \\
\hline 15 & 2552 & $5-\mathrm{MeC} 25$ & $12.4 \pm 2.0$ & $2.6 \pm 1.3$ \\
\hline 16 & 2564 & diMeC25 & $2.2 \pm 1.0$ & \\
\hline 17 & 2575 & 3-MeC25 & $2.7 \pm 0.7$ & $12.9 \pm 3.1$ \\
\hline 18 & 2582 & 5,y-diMeC25 & $3.2 \pm 1.3$ & \\
\hline 19 & 2600 & $\mathrm{n}-\mathrm{C} 26$ & $1.0 \pm 0.5$ & $2.5 \pm 0.9$ \\
\hline 20 & 2609 & 3,y-diMeC26 & $2.2 \pm 0.7$ & \\
\hline 21 & 2634 & $\mathrm{MeC} 26$ & $4.2 \pm 1.7$ & $1.0 \pm 0.4$ \\
\hline 22 & 2660 & Unidentified CHC & $0.5 \pm 0.3$ & $0.6 \pm 0.5$ \\
\hline 23 & 2678 & Unidentified CHC & $0.8 \pm 0.3$ & $8.8 \pm 3.3$ \\
\hline 24 & 2700 & $\mathrm{n}-\mathrm{C} 27$ & $2.4 \pm 1.8$ & $7.7 \pm 2.6$ \\
\hline 25 & 2734 & $9,11,13-\mathrm{MeC} 27$ & $5.3 \pm 2.0$ & $2.5 \pm 0.9$ \\
\hline 26 & 2752 & $5-\mathrm{MeC} 27$ & $2.2 \pm 0.6$ & $1.0 \pm 0.4$ \\
\hline 27 & 2761 & $\operatorname{diMeC} 27$ & $1.7 \pm 0.8$ & \\
\hline 28 & 2777 & $3-\mathrm{MeC} 27$ & $1.3 \pm 0.3$ & $2.4 \pm 0.7$ \\
\hline 29 & 2806 & 3,y-diMeC27 & $2.4 \pm 1.8$ & \\
\hline 30 & 2839 & Non-CHC & $0.9 \pm 0.5$ & \\
\hline 31 & 2864 & Unidentified CHC & $0.3 \pm 0.1$ & \\
\hline 32 & 2877 & $\mathrm{C} 29: 1$ & & $6.9 \pm 2.3$ \\
\hline 33 & 2900 & $\mathrm{n}-\mathrm{C} 29$ & $0.4 \pm 0.3$ & $1.7 \pm 1.2$ \\
\hline 34 & 2937 & $9,11,13-\mathrm{MeC} 29$ & $0.7 \pm 0.3$ & \\
\hline 35 & 2979 & Unidentified CHC & & $0.4 \pm 0.1$ \\
\hline 36 & 3069 & Unidentified CHC & & $0.2 \pm 0.2$ \\
\hline 37 & 3080 & $\mathrm{C} 31: 1$ & & $2.9 \pm 1.1$ \\
\hline 38 & 3152 & Non-CHC & $0.4 \pm 0.3$ & \\
\hline 39 & 3166 & Non-CHC & $0.7 \pm 1.1$ & \\
\hline 40 & 3182 & Non-CHC & $0.6 \pm 0.5$ & \\
\hline 41 & 3284 & $\mathrm{C} 33: 1$ & & $1.5 \pm 0.6$ \\
\hline
\end{tabular}

$\mathrm{RI}$, retention index; $\mathrm{Nr}$, peak number (peak numbers correspond to the peak numbering in Fig. 3).

that they are mostly found away from ants, but during nest sampling we also observed different obligate ant nest dwellers, such as multiple species of silverfish and the small beetle Cholovocera formicaria (Fig. S3). Interestingly, preliminary tests also showed that $C$. formicaria is a typical dweller of the Messor seed waste dumps (similar six-chamber laboratory nest localisation setup: 16 out of 26 individuals found in the chamber with organic debris). Other seed harvester ant genera, such as the Nearctic Veromessor (Uppstrom \& Klompen, 2011) and Pogonomyrmex ants (Lavigne, 1969; MacKay, 1983a, b;

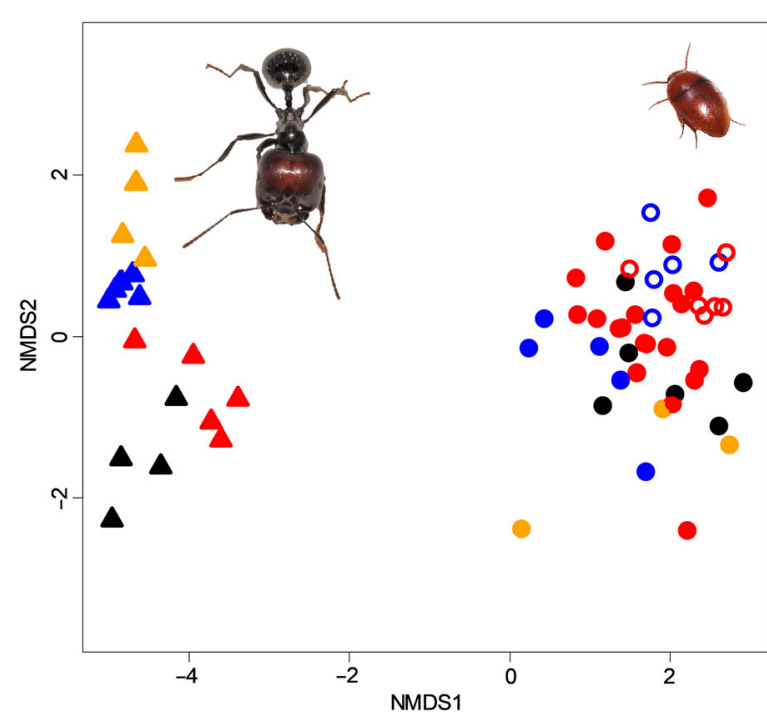

Fig. 4. Graphical representation of the dissimilarities between Messor barbarus and Oochrotus unicolor with a non-metric multidimensional scaling plot (stress $=0.09$ ). The underlying Euclidean distance matrix is based on the cuticular hydrocarbons (CHCs; $N=17$ ) shared by host and symbiont. Triangles, workers of $M$. barbarus; circles, O. unicolor; colours represent different nests (C1, red; C2, black; R1, blue; R3, orange). Open symbols depict beetles that were isolated for 11 days; the border colour of these symbols also codes for the nest origin. [Colour figure can be viewed at wileyonlinelibrary.com].

Cushing, 1998; Hendricks \& Hendricks, 1999), appear to attract a diverse community of arthropods as well.

Chemical mimicry prevails in specialised social insect symbionts that interact intimately with their host (reviewed in Table 1 in Parmentier et al., 2017a). They walk unnoticed among the host workers and solicit for food, are groomed and transported in the nest. Unspecialised species, on the other hand, have an idiosyncratic odour (Parmentier et al., 2017a) or may acquire the recognition cues passively (chemical camouflage) from their host by rubbing/feeding. As $O$. unicolor does not interact closely (no rubbing, grooming, food solicitation) with its host and as it is detected as a non-nest mate, it was surprising that its chemical cuticular profile showed significant similarities with its Messor host. The profile of the beetle hardly changed after isolation from its host ant. The aggression response was not higher towards isolated individuals, suggesting that the minor change in chemical profile was not biologically relevant. The stability of the profile indicates that the beetle is able to actively produce the blend of compounds itself rather than acquiring it passively from its host or nest material. Although speculative, the reasonable convergence in chemical odour could be the result of natural selection to smell more like the host, a process that has been perfected in very specialised myrmecophiles (Nash et al., 2008). Nevertheless, the chemical mimicry in the beetle is imperfect (cf.Witte et al., 2009; Pérez-Lachaud et al., 2015; von Beeren et al., 2018) and the beetles do provoke a mild form of aggression. The hydrocarbon profiles of Messor ants were colony-specific, but those of the beetle did not cluster with their host. There was only a weak difference in the beetle's 
cuticular profile across the host nests. Specialised myrmecophiles copy colony-specific hydrocarbon profiles (Nash et al., 2008; Nehring et al., 2016) and individuals transferred from other colonies of the host species experience higher levels of aggression (Elmes et al., 1999; Nehring et al., 2016). The lack of colony-specific similarity was reflected in similar behaviour of the ants towards associated beetles and those found in an alien $M$. barbarus colony. It has been hypothesised that a certain overlap in cues may already lower host aggression (Witte et al., 2009; Pérez-Lachaud et al., 2015; von Beeren et al., 2018). In addition, the absence of certain key recognition cues could also be under selection (chemical transparency) (Martin et al., 2008). The beetle also relies on mechanical defence and behaviour. It has a compact, tough and rounded exoskeleton. When detected, $O$. unicolor ducks to ground, meaning that the Messor ants cannot grab or pierce the beetles. We did not observe that the ants carried the beetles, as described in the Pogonomyrmex associate Araeoschizus airmeti (Hendricks \& Hendricks, 1999). Occasionally, Oochrotus beetles run away from their host. Altogether, the defence strategies of the beetle are very efficient, and we demonstrated that it is able to survive high densities of host workers.

The preferred host of $O$. unicolor are Messor ants (Wasmann, 1894; Soldati \& Soldati, 2000; R. Molero-Baltanás \& T. Parmentier, pers. obs.). Occasionally it is found with other ants, such as Aphaenogaster (Wasmann, 1894; R. Molero-Baltanás. pers. obs.) and it was reported with Camponotus sp. (Donisthorpe, 1927a) and Pheidole (Viñolas, 1982). Aggression tests revealed that ant species respond differently towards the beetle. Aphaenogaster and C. cruentatus were extremely tolerant and may serve as potential hosts. Probably nests from these ant species may be used as stepping stones to the more preferred Messor nests. Pheidole was extremely aggressive in the laboratory tests and the single reported association in the literature is therefore very doubtful (Viñolas, 1982).

Social insect nests are diversity hotspots for different types of symbionts. As predicted by coexistence theory (Chesson, 2000), species with long-living, stable nests and which provide different types of niches tend to attract the highest diversity of inquilines (Hughes et al., 2008). Waste dumps are widespread in social insect nests, but the biology of the symbionts living in this niche has received little attention so far. Nonetheless studies on the associates found in waste dumps across different lineages of social insects, such as bees (Bombus: Husband \& Brown, 1976; Rupp 1989), social wasps (Vespula: MacDonald et al., 1975; Akre et al., 1982; Rupp, 1989; Belonogaster: Keeping \& Crewe, 1983; Polistes: Nelson, 1968), termites (Kistner, 1982) and ants (general: Kistner, 1982; Hölldobler \& Wilson, 1990; army ants: Rettenmeyer et al., 2011; von Beeren et al., 2010; Lasius fuliginosus: Donisthorpe, 1927b; Hölldobler et al., 1981; leaf-cutter ants: Waller \& Moser, 1990, Verza et al., 2007; Platythyrea: Parmentier et al., 2017b), reveal that this niche is teeming with life. The diversity in this niche may rival or even outnumber the diversity of better-studied niches, such as the brood chambers or food chambers. The biology of most species is unknown and a large fraction is probably opportunistic and poorly adapted to this niche. However, we showed with the beetle $O$. unicolor that arthropods can be specialised to a waste dump niche. More research is needed to explore the biology and the variety of strategies found in dwellers of the waste dumps found in social insect societies. With this understanding, we will be able to assess better how the type of preferred niche is translated into the symbiont's strategies and its interactions with the host.

\section{Conclusion}

The beetle $O$. unicolor preferentially lives in the seed waste dumps of its Messor host. The beetle is rather unspecialised as it is detected as a non-nestmate and does not get the royal treatment such as that received by the most integrated myrmecophiles. Nevertheless, the beetle has a fairly specialised diet, which consists of debris of seeds found in abundance in its preferred niche. Moreover, the beetle actively produces a profile of CHCs that converge significantly with the nestmate recognition cues of its host. This chemical similarity together with a strong mechanical defence enables this beetle to live with its host.

\section{Acknowledgements}

This work has been funded by the University of Córdoba: 'XXIII Programa Propio de Fomento de la Investigación (2018): Modalidad 4.1. Ayudas para el desarrollo de proyectos de I+D precompetitivos', by the University of Ghent (BOF17/PDO/084) and by FWO-Vlaanderen.

\section{Author contributions}

TP designed the study, collected the study species, carried out the experimental trials and drafted the manuscript. MG participated in the design of the study, collected the study species and critically revised the manuscript. TW participated in the analysis of the chemical data and critically reviewed the draft. RM participated in the design of the study, collected the study species and critically revised the manuscript. The authors declare there are no competing interests.

\section{Supporting Information}

Additional supporting information may be found online in the Supporting Information section at the end of the article.

Fig. S1. The setup of the survival test of $O$. unicolor in a crowded chamber with M. barbarus.

Fig. S2. The Messor associates O. unicolor and Neoasterolepisma $\mathrm{sp}$.

Fig. S3. The Messor associates O. unicolor, Cholovocera formicaria (three individuals) and Neoasterolepisma sp. (partly displayed).

Video S1. Seed feeding and contest for seeds by $O$. unicolor

Video S2. Interactions between M. barbarus and O. unicolor

\section{References}

Aitchison, J. (1986) The statistical analysis of compositional data. Chapman and Hall, London, UK. 
Akino, T. \& Knapp, J. (1999) Chemical mimicry and host specificity in the butterfly Maculinea rebeli, a social parasite of Myrmica ant colonies. Proceedings of the Royal Society B: Biological Sciences, 266, 1419-1426.

Akre, R.D., Reed, H.C. \& Landolt, P.J. (1982) Nesting biology and behavior of the blackjacket, Vespula consobrina (Hymenoptera: Vespidae). Journal of the Kansas Entomological Society, 55, 373-405.

Allsopp, P. (1980) The biology of false wireworms and their adults (soil-inhabiting Tenebrionidae) (Coleoptera): a review. Bulletin of Entomological Research, 70, 343-379.

AntWiki (2019) http://www.antwiki.org/ [accessed on 10 August 2019].

Armbruster, P., Hutchinson, R.A. \& Cotgreave, P. (2002) Factors influencing community structure in a south American tank bromeliad fauna. Oikos, 96, 225-234.

Biani, N.B., Mueller, U.G. \& Wcislo, W.T. (2009) Cleaner mites: sanitary mutualism in the miniature ecosystem of Neotropical bee nests. The American Naturalist, 173, 841-847.

Bot, A.N.M., Currie, C.R., Hart, A.G. \& Boomsma, J.J. (2001) Waste management in leaf-cutting ants. Ethology Ecology \& Evolution, 13, 225-237.

Brendonck, L., Jocqué, M., Tuytens, K., Timms, B.V. \& Vanschoenwinkel, B. (2015) Hydrological stability drives both local and regional diversity patterns in rock pool metacommunities. Oikos, 124, $741-749$.

Browne, W.J., Subramanian, S.V., Jones, K. \& Goldstein, H. (2005) Variance partitioning in multilevel logistics models with over-dispersion. Journal of Royal Statistical Society A, 168, 599-613.

Cammaerts, R. (1995) Regurgitation behaviour of the Lasius flavus worker (Formicidae) towards the myrmecophilous beetle Claviger testaceus (Pselaphidae) and other recipients. Behavioural Processes, 34, 241-264.

Cerdá, X. \& Retana, J. (1994) Food exploitation patterns of two sympatric seed-harvesting ants Messor bouvieri (Bond.) and Messor capitatus (Latr.) (Hym., Formicidae) from Spain. Journal of Applied Entomology, 117, 268-277.

Cerdan, P. (1989) Etude de la biologie, de l'écologie et du comportement des fourmis moissonneuses du genre Messor (Hymenoptera, Formicidae) en Crau.

Chesson, P. (2000) Mechanisms of maintenance of species diversity. Annual Review of Ecology and Systematics, 31, 343-366.

Clark, W.H. \& Blom, P.E. (1988) Observations on the relationship between ants (Hymenoptera: Formicidae: Myrmicinae, Dorylinae) and Araeoschizus (Coleoptera: Tenebrionidae). Journal of the Idaho Academy of Science, 24, 34-37.

Cristaldo, P.F., Rosa, C.S., Florencio, D.F., Marins, A. \& DeSouza, O. (2012) Termitarium volume as a determinant of invasion by obligatory termitophiles and inquilines in the nests of Constrictotermes cyphergaster (Termitidae, Nasutitermitinae). Insectes Sociaux, 59, 541-548.

Cushing, P.E. (1998) Population structure of the ant nest symbiont Masoncus pogonophilus (Araneae: Linyphiidae). Annals of the Entomological Society of America, 91, 626-631.

Di Giulio, A., Maurizi, E., Barbero, F., Sala, M., Fattorini, S., Balletto, E. et al. (2015) The pied piper: a parasitic beetle's melodies modulate ant behaviours. PLoS One, 10, e 0130541.

Donisthorpe, H.S.J.K. (1927a) The ants (Formicidae), and some myrmecophiles, of Sicily. The Entomologist's. Record, 39, 5-9.

Donisthorpe, H.S.J.K. (1927b) The guests of British ants, their habits and life-histories. George Routledge and Sons, London, U.K.

Elmes, G.W., Barr, B., Thomas, J.A. \& Clarke, R.T. (1999) Extreme host specificity by Microdon mutabilis (Diptera: Syrphidae), a social parasite of ants. Proceedings of the Royal Society of London B, 266, $447-453$.
Fine, P.V.A. (2015) Ecological and evolutionary drivers of geographic variation in species diversity. Annual Review of Ecology, Evolution, and Systematics, 46, 369-392.

Hart, A.G. (2002) Waste management in the leaf-cutting ant Atta colombica. Behavioral Ecology, 13, 224-231.

Hendricks, P. \& Hendricks, L.M. (1999) Field observations on the myrmecophilous beetle Araeoschizus airmeti Tanner (Coleoptera: Tenebrionidae) at harvester ant (Hymenoptera: Formicidae) mounds. Great Basin Naturalist, 59, 297-299.

Hölldobler, B. (1967) Zur Physiologie der Gast-Wirt-Beziehungen (Myrmecophilie) bei Ameisen I. Das Gastverhältnis der Atemeles- und Lomechusa-Larven (Col. Staphylinidae) zu Formica (Hym. Formicidae). Zeitschrft für vergleichende Physiologie, 56, 1-21.

Hölldobler, B. \& Wilson, E.O. (1990) The ants. Harvard University Press, Cambridge, Massachusetts.

Hölldobler, B., Möglich, M. \& Maschwitz, U. (1981) Myrmecophilic relationship of Pella (Coleoptera: Staphylinidae) to Lasius fuliginosus (Hymenoptera: Formicidae). Psyche: A Journal of Entomology, 88, 347-374.

Hughes, D.P., Pierce, N.E. \& Boomsma, J.J. (2008) Social insect symbionts: evolution in homeostatic fortresses. Trends in Ecology and Evolution, 23, 672-677.

Husband, R.W. \& Brown, T.M. (1976) Insects associated with Michigan bumble bees (Bombus spp.). The Great Lakes Entomologist, 9, 57-62.

Johnson, R. (2001) Biogeography and community structure of north American seed-harvester ants. Annual Review of Entomology, 46, $1-29$.

Keeping, M.G. \& Crewe, R.M. (1983) Parasitoids, commensals and colony size in nests of Belonogaster (Hymenoptera, Vespidae). Journal of the Entomological Society of Southern Africa, 46, 309-323.

Kistner, D.H. (1979) Social and evolutionary significance of social insect symbionts. Social Insects (ed. by H. R. Herman), pp. 339-413. Academic Press, San Francisco, Londen.

Kistner, D.H. (1982) The social insects' bestiary. Social insects, Vol. 3 (ed. by H. R. Hermann), pp. 1-244. Academic Press, New York.

Krieger, J.R. \& Kourtev, P.S. (2012) Bacterial diversity in three distinct sub-habitats within the pitchers of the northern pitcher plant, Sarracenia purpurea. FEMS Microbiology Ecology, 79, 555-567.

Kronauer, D.J.C. \& Pierce, N.E. (2011) Myrmecophiles. Current Biology, 21, 208-209.

Lachaud, J.P. \& Pérez-Lachaud, G. (2015) Ectaheteromorph ants also host highly diverse parasitic communities: a review of parasitoids of the Neotropical genus Ectatomma. Insectes Sociaux, 62, 121-132.

Lavigne, R.J. (1969) Bionomics and nest structure of Pogonomyrmex occidentalis (Hymenoptera: Formicidae). Annals of the Entomological Society of America, 62, 1166-1175.

MacDonald, J.F., Akre, R.D. \& Hill, W.B. (1975) Nest Associates of Vespula atropilosa and $V$. pensylvanica in southeastern Washington state (Hymenoptera: Vespidae). Journal of the Kansas Entomological Society, 48, 53-63.

MacKay, W.P. (1983a) Beetles associated with the harvester ants, Pogonomyrmex montanus, P. subnitidus and P. rugosus (Hymenoptera: Formicidae). Coleopterist Bullettin, 37, 239-246.

MacKay, W.P. (1983b) Echinocoleus setiger Horn (Coleoptera: Leiodidae), an inquiline in the nest of Pogonomyrmex spp. (Hymenoptera: Formicidae). Proceedings of the Entomological Society of Washington, 85, 698-703.

Martin, S.J., Takahashi, J.-I., Ono, M. \& Drijfhout, F.P. (2008) Is the social parasite Vespa dybowskii using chemical transparency to get her eggs accepted? Journal of Insect Physiology, 54, 700-707.

Messadi, D., Helaimia, F., Ali-Mokhnache, S. \& Boumahraz, M. (1990) Accurate determination of retention indices in programmed temperature gas chromatography. Chromatographia, 29, 429-434. 
Molero-Baltanás, R., Bach De Roca, C., Tinaut, A., Pérez, J.D. \& Gaju-Ricart, M. (2017) Symbiotic relationships between silverfish (Zygentoma: Lepismatidae, Nicoletiidae) and ants (Hymenoptera: Formicidae) in the Western Palaearctic. A quantitative analysis of data from Spain. Myrmecological News, 24, 107-122.

Molero-Baltanás, R., Gaju-Ricart, M. \& Bach De Roca, C. (1998) Myrmecophilic Zygentoma (insects: Apterygota) from the Ibero-Balearic fauna-biogeographic remarks. Pedobiologia, 46, 284-295.

Nash, D.R., Als, T.D., Maile, R., Jones, G.R. \& Boomsma, J.J. (2008) A mosaic of chemical coevolution in a large blue butterfly. Science, 319, 88-90.

Nehring, V., Dani, F.R., Calamai, L., Turillazzi, S., Bohn, H., Klass, K.-D. et al. (2016) Chemical disguise of myrmecophilous cockroaches and its implications for understanding nestmate recognition mechanisms in leaf-cutting ants. BMC Ecology, 16, 35.

Nelson, J.M. (1968) Parasites and symbionts of nests of Polistes wasps. Annals of the Entomological Society of America, 61, 1528-1539.

Parmentier, T., Bouillon, S., Dekoninck, W. \& Wenseleers, T. (2016a) Trophic interactions in an ant nest microcosm: a combined experimental and stable isotope $\left(\delta^{13} \mathrm{C} / \delta^{15} \mathrm{~N}\right)$ approach. Oikos, 125, $1182-1192$.

Parmentier, T., Dekoninck, W. \& Wenseleers, T. (2016b) Do well-integrated species of an inquiline community have a lower brood predation tendency? A test using red wood ant myrmecophiles. BMC Evolutionary Biology, 16, 12.

Parmentier, T., Dekoninck, W. \& Wenseleers, T. (2017a) Arthropods associate with their red wood ant host without matching nestmate recognition cues. Journal of Chemical Ecology, 43, 644-661.

Parmentier, T., Yéo, K., Dekoninck, W. \& Wenseleers, T. (2017b) An apparent mutualism between Afrotropical ant species sharing the same nest. Behavioral Ecology and Sociobiology, 71, 46.

Parmentier, T., de Laender, F., Wenseleers, T. \& Bonte, D. (2018) Prudent behavior rather than chemical deception enables a parasite to exploit its ant host. Behavioral Ecology, 29, 1225-1233.

Pérez-Lachaud, G., Bartolo-Reyes, J.C., Quiroa-Montalván, C.M., Cruz-Lopez, L., Lenoir, A. \& Lachaud, J.P. (2015) How to escape from the host nest: imperfect chemical mimicry in eucharitid parasitoids and exploitation of the ants' hygienic behavior. Journal of Insect Physiology, 75, 63-72.

Rettenmeyer, C.W., Rettenmeyer, M.E., Joseph, J. \& Berghoff, S.M. (2011) The largest animal association centered on one species: the army ant Eciton burchellii and its more than 300 associates. Insectes Sociaux, 58, 281-292.

Richardson, B.A. (1999) The bromeliad microcosm and the assessment of faunal Diversity. Biotropica, 31, 321-336.

Rosengren, R., Fortelius, W., Lindström, K. \& Luther, A. (1987) Phenology and causation of nest heating and thermoregulation in red wood ants of the Formica rufa group studied in coniferous forest habitats in southern Finland. Annales Zoologici Fennici, 24, 147-155.
Rupp, L. (1989) The central European species of the genus Volucella (Diptera, Syrphidae) as commensals and parasitoids in the nests of bumblebees and social wasps: studies on host-finding, larval biology and mimicry:

Sánchez-Piñero, F. \& Gómez, J.M. (1995) Use of ant-nest debris by darkling beetles and other arthropod species in an arid system in South Europe. Journal of Arid Environments, 31, 91-104.

Seifert, B. (2007) Die Ameisen Mittel- und Nordeuropas. lutra Verlagsund Vertriebsgesellschaft, Görlitz.

Soldati, F. \& Soldati, L. (2000) A propos d' Oochrotus unicolor Lucas, 1852 (Coleoptera Tenebrionidae). Bulletin of the Linnean Society of Bordeaux, 28, 181-187.

Steinberger, Y., Leschner, H. \& Shmida, A. (1991) Chaff piles of harvester ant (Messor sp.) nests in a desert ecosystem. Insectes Sociaux, 38, 241-250.

Uppstrom, K.A. \& Klompen, H. (2011) Mites (Acari) associated with the desert seed harvester ant, Messor pergandei (Mayr). Psyche, 2011, 1-7.

van Zweden, J.S. \& d'Ettorre, P. (2010) Nestmate recognition in social insects and the role of hydrocarbons. In Insect hydrocarbons biology, biochemistry and chemical ecology, p. 492. Cambridge University Press, New York, New York.

Verza, S.S., Forti, L.C., Lopes, J.F.S. \& Hughes, W.O.H. (2007) Nest architecture of the leaf-cutting ant Acromyrmex rugosus rugosus. Insectes Sociaux, 54, 303-309.

Viñolas, A. (1982) Tenebriónidos de la comarca del Segrià y de las zonas halófilas de Los Monegros. II Sessió conjunta d'entomologia/Barcelona, ICHNSCL, 2, 67-72.

von Beeren, C., Brückner, A., Maruyama, M., Burke, G., Wieschollek, J. \& Kronauer, D.J.C. (2018) Chemical and behavioral integration of army ant-associated rove beetles - a comparison between specialists and generalists. Frontiers in Zoology, 15, 8.

von Beeren, C., Maruyama, M., Hashim, R. \& Witte, V. (2010) Differential host defense against multiple parasites in ants. Evolutionary Ecology, 25, 259-276.

Waller, D.A. \& Moser, J.C. (1990) Invertebrate enemies and nest associates of the leaf-cutting ant Atta texana (Buckley) (Formicidae, Attini). Applied myrmecology, a world perspective, 256-273.

Wasmann, E. (1894) Kritisches Verzeichniss der myrmekophilen und termitophilen Arthropoden. F. L. Dames, xv, Berlin, Germany.

Wilson, E.O. (1971) The insect societies. Belknap Press, Cambridge, Massachusetts.

Witte, V., Foitzik, S., Hashim, R., Maschwitz, U. \& Schulz, S. (2009) Fine tuning of social integration by two myrmecophiles of the ponerine army ant, Leptogenys distinguenda. Journal of Chemical Ecology, 35, 355-367.

Accepted 5 December 2019

Associate Editor: Simon Robson 